\title{
Conjectures to the Memes of Indonesian Songs
}

\author{
Hokky Situngkir \\ [hs@compsoc.bandungfe.net] \\ Dept. Computational Sociology \\ Bandung Fe Institute
}

\begin{abstract}
From the works of mathematical properties of songs, we construct the phylomemetic trees of Indonesian ethnic and traditional songs. The memeplexes are then reflected by the used notes and respective durations as they exhibit the Zipf-Mandelbrot law, the gyration coefficient, "spiraling effects", and the dynamic entropy shown in the structure of the songs. The cladistic techniques yielding phylomemetic tree shows widespread innovations of the songs sampled in the observation. This is however reflects the cultural evolutionary models for the innovations involve generations of people within ethnic groups. The paper ends with open discussions and conjectures for more detailed discussions related to each traditional songs as well as the properties of Indonesian people that are attached to heterogeneous ethnic groups that are continually swarming songs and in general, other aesthetic audible artifacts.
\end{abstract}

Keywords: Indonesian ethnic songs, memetics, phylomemetic tree. 
A true tradition is not the witnessing of a past closed and finished; it is a living force that animates and informs the present.

-IGOR STRAVINSKY

\section{Introduction}

The richness of variations in Indonesian ethnic groups implies to the great deal of variations of the concepts of aesthetics. Each ethnicity emerges the customs and we can observe the emerging collective "taste" of every ethnic group by diving into the information extraction of the artifacts. One of important things about this is how people taste music and things that can be categorized as beautiful sounds. Here, as it has been cited in [6: 208], the ethnic identities (including national one) are reflected upon phantasmic possession of a definitive core pleasure. Thus it becomes very relevant that from the landscape of the ethnic groups in Indonesia, we could see each unique folk songs to reflect the way ethnicities developed evolutionarily. Some of them are even attached so deeply with their customs and traditions (cf. [2]). From previous work, we have seen how we could extract some mathematical information from monophonic melody of Indonesian songs, i.e. .: folk/traditional songs, national songs, and popular songs [9]. Furthermore, the extraction information can bring us to the way the songs can be categorized into the three genres of music as perceived by Indonesian people [10].

The next task that we would like to present in this paper is employing the memetic analysis to the statistical mechanics and mathematical information extraction that we have provided before. There is some difference in the approach incorporated in this paper with the detailed observation proposed by [5]. Yet, what we offer here is things related to the ability to see musical artifacts in its information extraction processes as shown in [4]. We accentuate the use of mathematical observation in its deliverance of what may reveal not only from the notes and their sequences in the music corpora. This is an interesting observation since it brings us to the tour of the audible sides of the diversities embedded in Indonesian ethnic groups. While the unique sounds emerge from the traditional heritages substrate, we are conjectured to have a big picture to the rich musical aspects while gazing through Indonesian contingent multicultural living.

The structure of the paper is as follows. We begin by revisiting the aspects of mathematical representation of song and contrasting it to the study of meme as the elements emerged from the songs. Regarding to our analytical objects, i.e.: folk and traditional songs, it is worth noting that we use the most common interpretation of notational aspects of the songs. It has been widely realized that folk songs do not have a singular canonical version for they are sung so often and common people do not strongly and objectively use the correct key [6: 148]. From this realization, we use the concept of statistical correlations to transform the variables we obtained from the traditional songs into distances between the nodes representing the specific artifacts. This method has been discussed in [11].

\section{Songs and its Memetic Reflection}

Our data mine is conducted as explained in [10], thus we analyze the monophonic data. It is important to note that the song we use here is not simply a song with traditional and ethnic language, but songs that has been widely recognized to be emerged within the respective ethnic society. Thus, a lot of songs that it has been recorded to be written and composed by certain modern artist are excluded in the analysis. This is worth since a lot of nation-wide popular - to be - 
ethnic songs has been influenced by modern (western) musical realms. Since we are motivated to relate the properties of the ethnicity with traditional musical works of art, we choose only those who has been understood and widely acknowledged original and attached not to particular composer/artist but to the ethnic society in which the song is emerged.

This can be accepted for most Indonesian folk songs are melodic instead of harmonic. Some examples can be seen in Indonesian folk songs' book bank [8]. We incorporates analytical approach which details can be accessed in [9] and [10]. In table 1, the summary of the used variables to fill in the memeplexes of each songs are elaborated.

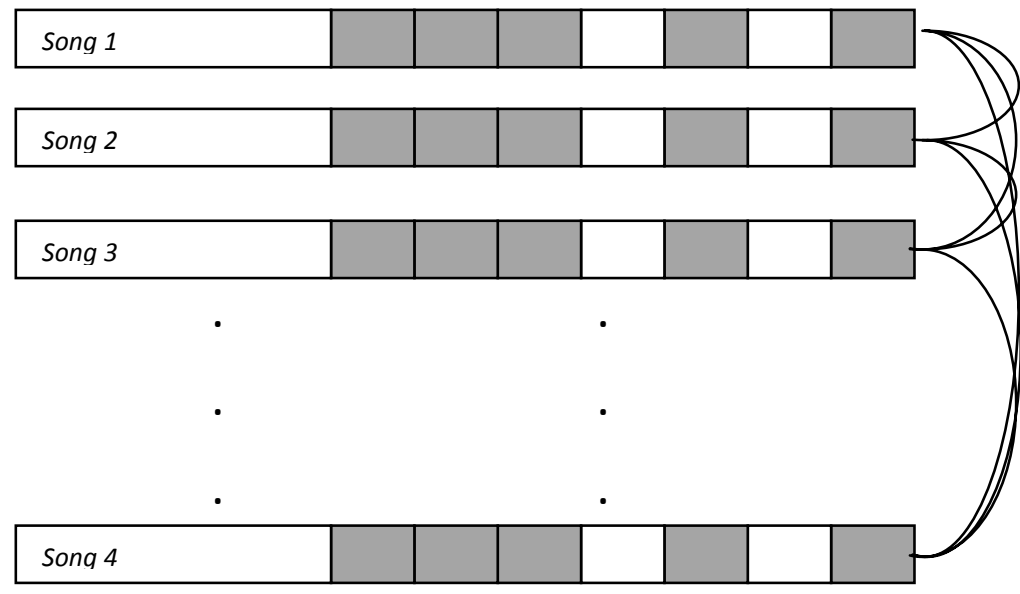

Figure 1

The memeplexes reflection that represent each song are lined up to find the distances by incorporating correlation method.

A singular sounds represented a single frequency in the audible spectrum is not a song and thus not a meme. But sequences of notes played with certain durations or beats could attach to us aesthetically as we discover it an enjoyable song. Some songs can only be appreciated by certain people while other have more population that attach into. While diversities grows in a geographical landscapes like Indonesia which nation-wide population are composed by more than 500 ethnic groups spreading in the archipelago, traditional songs are sung by folks. The remaining questions are the differentiation among the songs that become friendly to us, as we perceived now as part of Indonesian national cultural heritage.

Traditional songs have widely recognized as one of important aspects differentiating an ethnic identities with another. However, there have not yet been an extensive research related to the differentiation of them that can lead us to comprehensive understanding related to the big picture of aesthetically appreciated sounds to Indonesian people. Although we realize that this is too much to be expected from the work presented here, this can be understood as first step to build a conjecture to larger need. 
Table 1

Variables Used as Representation of the Memeplex

\begin{tabular}{|c|c|c|}
\hline Aspects & Feature & Representation \\
\hline $\begin{array}{l}\text { Zipf-Mandelbrot } \\
\text { aspects [9] }\end{array}$ & $\begin{array}{l}\text { From the fitting coefficients of the Zipf- } \\
\text { Mandelbrot Law showing the best fit of } \\
\text { the ranking of the usage of notes and } \\
\text { durations in the respective song. The } \\
\text { variables are } a, b \text {, and } c \text { in equation } \\
f(r)=\frac{a}{(1+b r)^{2}} \text { where } r \text { is the } \\
\text { ranking of respective notes and } \\
\text { durations employed in the song. }\end{array}$ & $\begin{array}{l}\text { The three variables emerges the } \\
\text { complex statistical features of } \\
\text { song's acquisitions of notes and } \\
\text { durations. It, quantitatively } \\
\text { speaking, is reflected the usage of } \\
\text { particular notes on respective } \\
\text { durations related to one another. }\end{array}$ \\
\hline $\begin{array}{l}\text { Gyration Coefficient } \\
{[4,10]}\end{array}$ & $\begin{array}{l}\text { If we plot the song in its nodes and } \\
\text { durations on the landscape of } \\
\theta(t) \text { vs } \theta(t+1) \text { where } \theta(t) \text { represents } \\
\text { the notes and durations in time } t \text {, then } \\
\text { we can calculate how far the } \\
\text { notes/durations are separated from } \\
\text { the axis yielded from the linear fit of } \\
\text { the scattered notes/durations. }\end{array}$ & $\begin{array}{l}\text { The bigger its value the more } \\
\text { compact the song. Related to its } \\
\text { properties, this variable shows the } \\
\text { compactness of the song when it is } \\
\text { played or heard. }\end{array}$ \\
\hline $\begin{array}{l}\text { Spiraling Effect [4, } \\
10]\end{array}$ & $\begin{array}{l}\text { By visualizing the ascending sorted of } \\
\text { the } \theta(t) \text { in the radial representation, } \\
\text { we could fit the yielded spiral with the } \\
\text { logarithmic spiral of } \rho(\phi) \sim \exp (\phi) \\
\text { showing how far the used notes and } \\
\text { durations repelled from the gyration } \\
\text { axis of the song. }\end{array}$ & $\begin{array}{l}\text { Showing the dynamicity of songs } \\
\text { from the lowest to the highest } \\
\text { value of } \theta(t) \text {. The quantity reflects } \\
\text { further and consequently more } \\
\text { dynamics usage of the notes in the } \\
\text { songs. }\end{array}$ \\
\hline Entropy $[4,10,12]$ & $\begin{array}{l}\text { The statistical measurement related to } \\
\text { the number of the total microstates } \\
\text { within the song, } S=\log _{2} N \text {, where } N \\
\text { is the total types of notes/duration. } \\
\text { This number of microstates relatively in } \\
\text { the ending and beginning of the song } \\
\text { shows the levels of the song's } \\
\text { complexity or disorderliness. }\end{array}$ & $\begin{array}{l}\text { The more this value, the more } \\
\text { microstates incorporated within } \\
\text { song. While a meme, qualitatively } \\
\text { speaking, can be related to simply } \\
\text { one notes (with respective } \\
\text { durations) [cf. 2], this variable } \\
\text { shows the elementary richness of } \\
\text { the notes/durations acquisitions in } \\
\text { song's melodic structure. }\end{array}$ \\
\hline Negentropy $[4,10]$ & $\begin{array}{l}\text { The parameter showing the degree of } \\
\text { organization, or simply speaking, the } \\
\text { order of the song. Roughly speaking, it } \\
\text { reflects things opposite to what is tried } \\
\text { to be delivered by "entropy". }\end{array}$ & $\begin{array}{l}\text { The more this value the more the } \\
\text { order of the songs, and vice versa. } \\
\text { This can be related to the } \\
\text { complexity of the song, a thing } \\
\text { perceived by listener of the song. A } \\
\text { simple song is reflected with higher } \\
\text { Negentropy while the more } \\
\text { complex one emerges lower one. } \\
\text { From [9] it has been discussed that } \\
\text { songs are composed with an } \\
\text { abstract aiming to higher the level } \\
\text { of notes/durations organization } \\
\text { while dynamically they show lower. }\end{array}$ \\
\hline
\end{tabular}




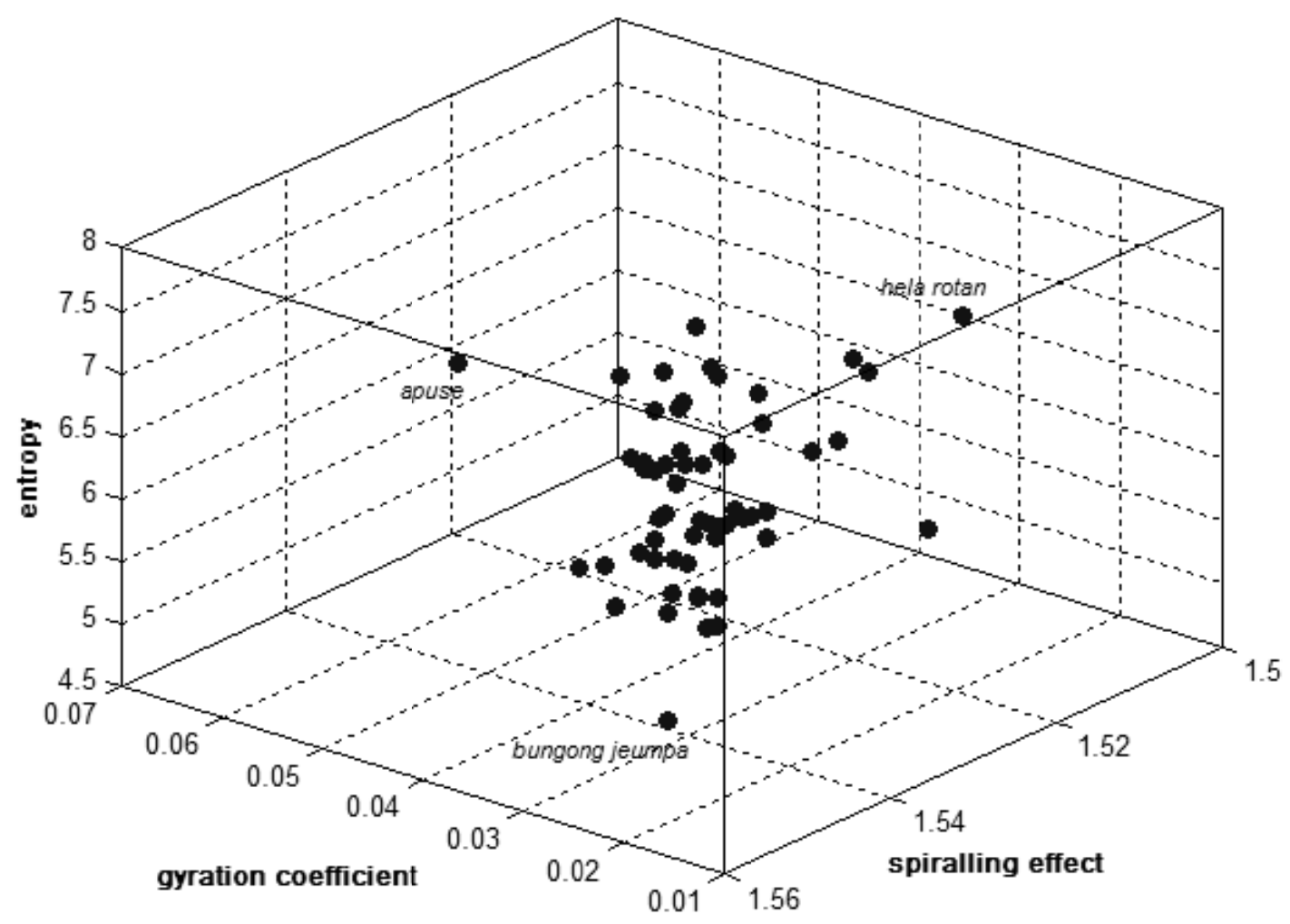

Figure 2

The scattering of gyration coefficients, spiraling effect, and entropy of some Indonesian traditional songs.

In our observation, we extract information related to the observed songs, i.e.: the statistical aspects of the notes used along with their durations, the 'movement' of the song from the gyration coefficient and spiraling effects, and the composition of the songs by borrowing some concepts from entropy and the emerged calculated order (negentropy). This is expected becoming a quantitative approach to the works of art as social representation and a way to see the collective states of memes among the circles of ethnic groups. The construction of memeplexes here proposes that the meme as reflected in a song is not merely just a note (as to what people literally understood from Dawkins' clause) but wider and more complex related to the use and choice of notes, the vibe that might be brought by such structure and composition and the dynamics delivers by song as it is sung.

Figure 2 shows the scattering properties of the Indonesian songs as presented in the paper. From the figure we could see that the song "apuse" (from Papua), "es lilin" (West Java), and "gorogorone" (Maluku) are three songs with highest gyration coefficient while "rambadia" (Tapanuli), "kambanglah bungo" (West Sumatera), and "Bungong Jeumpa" (Aceh) are three with the lowest one. The first three songs are considered to be the most compact songs relative to other songs in the terms of the used notes and durations within the songs. In turn, by listening to the latest three songs, we could recognize the songs are rich with changes in notes and durations. This is confirmed by the findings that song "bungong jeumpa", followed by "indologo" (Bugis) and "rambadia" (Tapanuli) are the traditional songs with highest spiraling effects. However, songs like "oleh sioh" (Maluku), "buka pintu" (Maluku), followed by "keroncong kemayoran" (Betawi) are songs which highest entropy. 


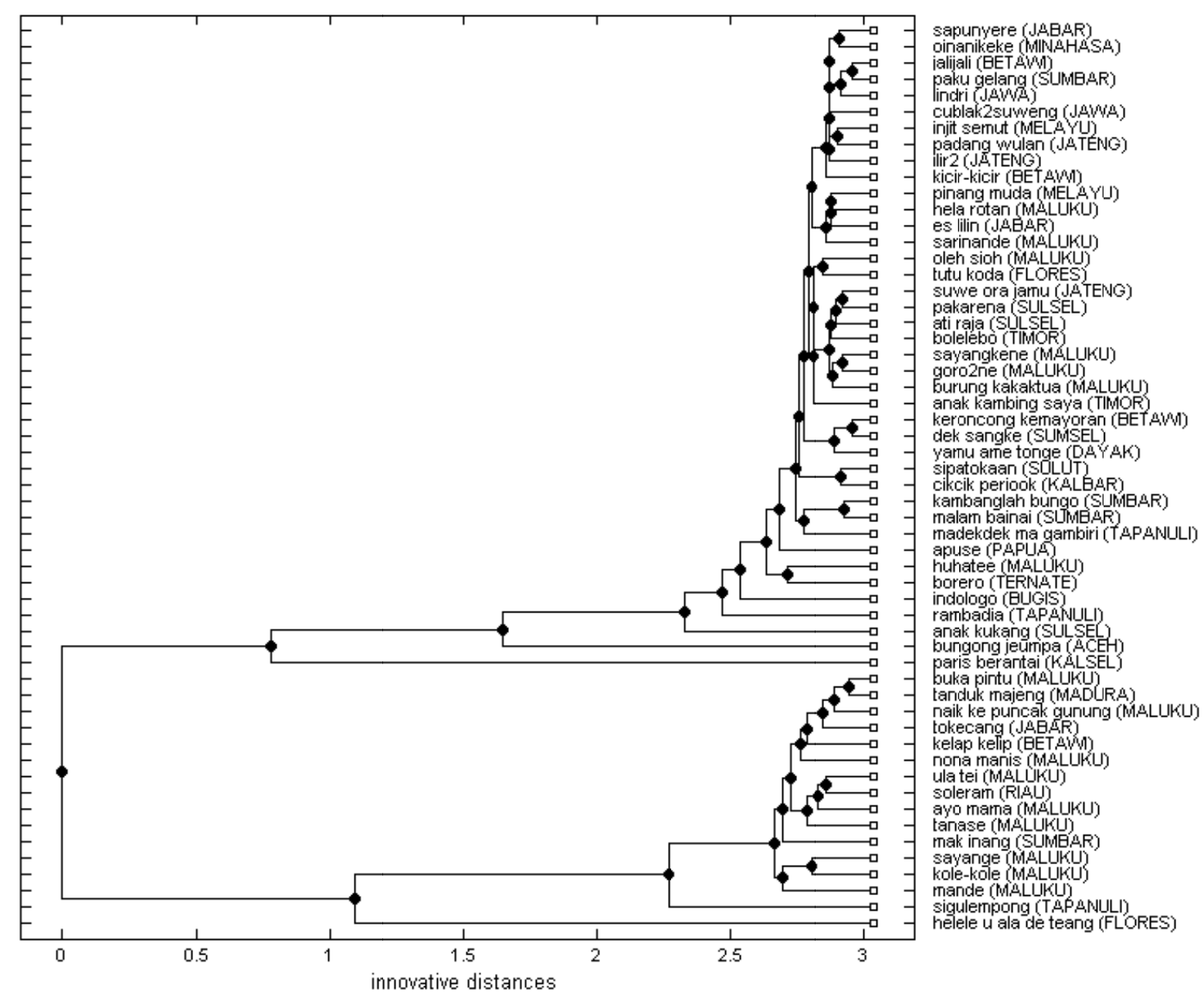

Figure 3

The phylomemetic representation of Indonesian traditional songs

\section{Phylomemetic Tree of Indonesian Folk Songs}

How those songs represented in the complex clustering related to the variables assumed to be the memeplexes of the songs are becoming the task of the cladistics of the phylomemetic tree we would like to present. This is brought by applying the algorithm introduced in [11]. The songs are thus can be visualized in figure 3. Interestingly, we could see that the songs (that are recognized to be originally emerged from ethnic social life for their anonymity) are clustered in two big groups. One of the groups is dominated with songs from Maluku as also giving most contributions of the sample used in this observation. In the big picture, it is interesting to discover that the ethnic signatures are dissolved not to be so explicit in some particular clusters. For instance, the song from Betawi (Jalijali) is so close to a song from Malayan West Sumatera (Pakugelang). From figure 4, it is clear that from the contours of the both songs, the similarity is emerged.

The memetic relation as reflected between two songs is the complex mixtures as presented in the yielded phylomemetic tree. It could come from the similar contours, the structure of the songs, the spiraling effect from the signatures of each song, and a lot more. For instance, the relation between the two Betawi songs Jali-jali with Paku Gelang (West Sumatera) could be dominated by the similar contours of the chosen notes the respectice durations each note played. Another interesting facts 
can be seen as shown in figure 5. Here, we could see the strong similarities of spiraling effect presented by Keroncong Kemayoran and Dek Sangke (South Sumatera). In both songs, the fast notes transitions giving the circling aesthetic sounds are ended in the relatively same notes with same durations (the $4 / 4$ added with $1 / 4$ notes).
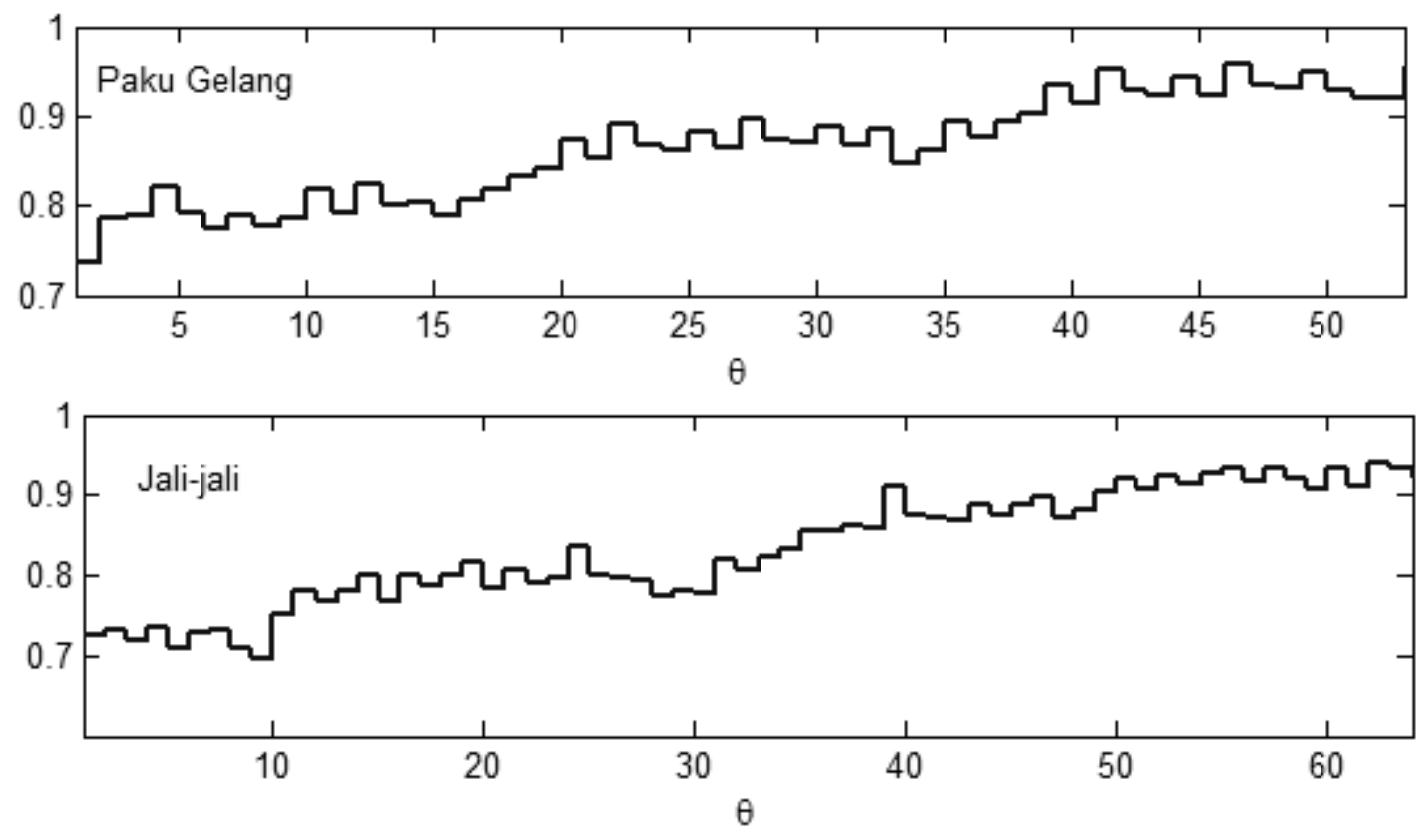

Figure 4

The comparison of the very close musical contour of songs from Sumatera Barat (Paku Gelang) and the Betawi (Jali-jali).

From these two Betawi songs, we could see that there is a strong relations between Malay influences that could probably came from the characteristics of the coastal culture of Betawi. Betawi is the ethnic groups that are concentrated in the capitol of Indonesia thus the aesthetic affection from a lot of ethnic groups are inevitable - a thing that also brings us to the colorful patterns of Betawi culture, generally speaking. This also accentuates by the spreading and clustering patterns in songs from Maluku. Some Maluku songs are highly clustered in one big cluster in the phylomemetic tree while in the other one, they also present grouped with songs from other ethnic groups. Some songs are closed with songs from West Java and Malay (e.g.: Sarinande) while some other are related to songs from Sulawesi and Central Java. Nonetheless, the latest clustering patterns still have explicitly showing the differences between the songs from each geographical places that are connected by sea and oceans (Maluku, Timor and Southern Sulawesi).
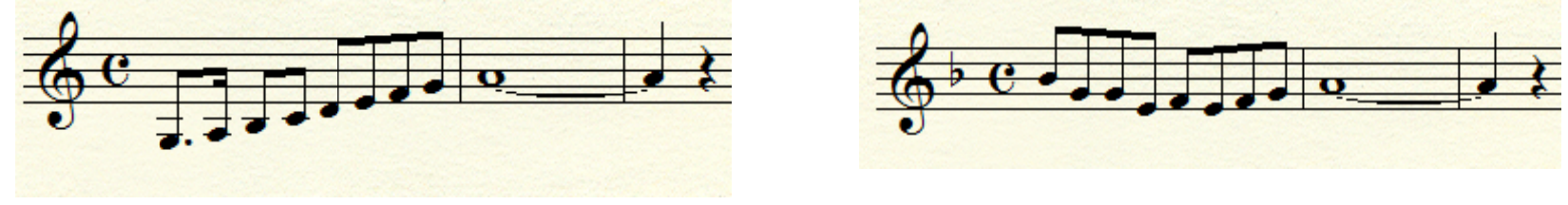

Figure 5

Spiralling effect in Keroncong Kemayoran (Betawi) and Dek Sangke (South Sumatera) songs as the basis for the close relation between the two songs in the phylomemetic tree. 


\section{Closing Remarks}

There are a lot of musical properties that distinguishes one Indonesian songs to another. The diversities might come for the differences places and social interactions in which the particular songs were born. From the mathematical properties of the Zipf-Mandelbrot law exhibited in note sequences in our samples added with the modeling of song properties of gyration, spiraling effects, and the entropy and complexity emerged in traditional songs, the phylomemetic tree is visualized. The ethnic songs are however become an important identities for each ethnic groups as one collective identities composing the diversity of Indonesia as a whole. The radial representation of the resulted phylomemetic tree is shown in figure 6 .

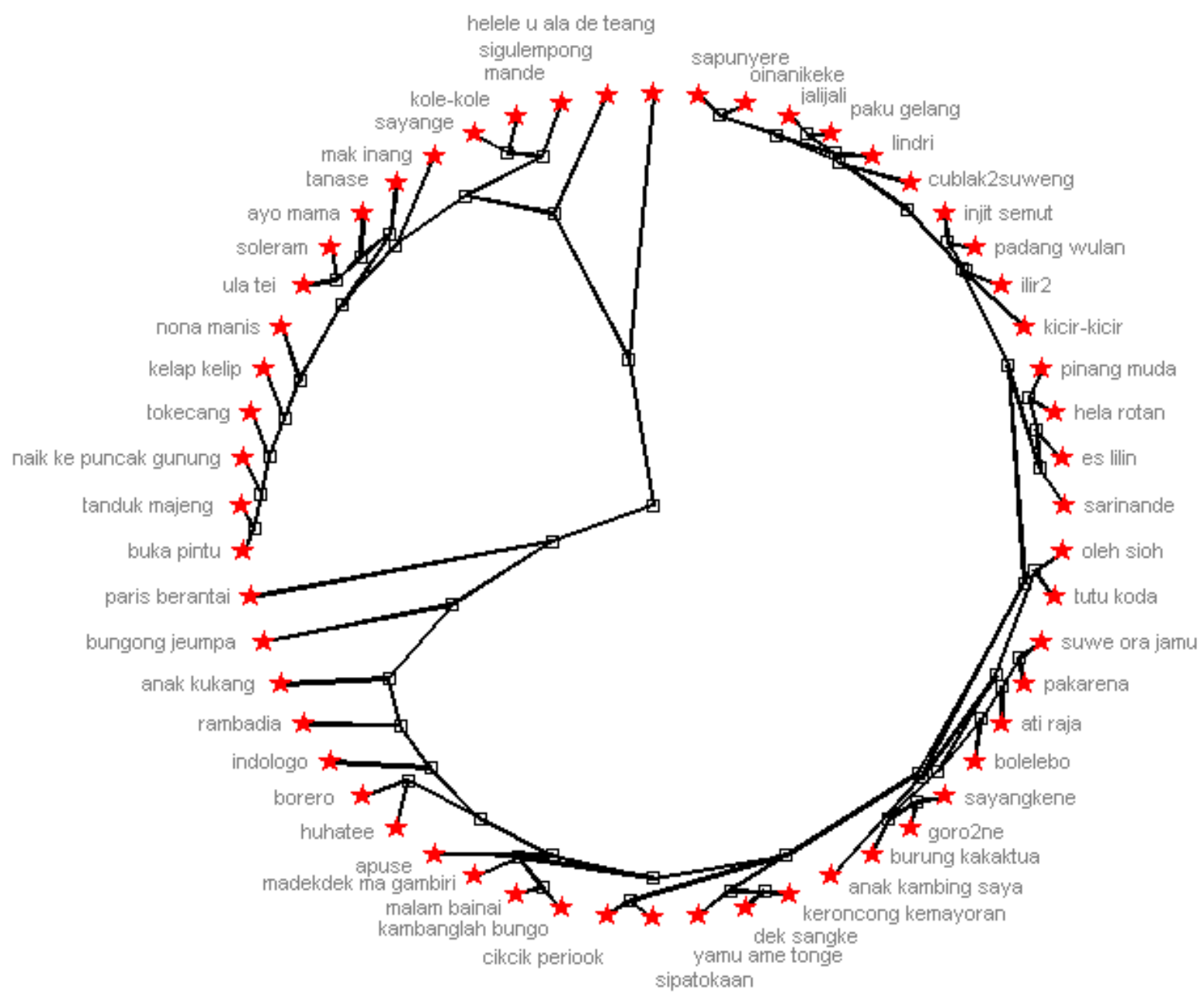

Figure 6

The radial phylomemetic representation of Indonesian traditional songs.

The visualization of the Indonesian traditional songs can, somehow, brought us to a lot of discussions for further aesthetic properties of the sampled songs as well as the features emerged from each collective identities. As it has been exemplified in the discussions of two Betawi songs in the previous sections, things related to the songs and audible properties attached to the innovations through generations in each ethnic groups are open towards more detail discussions. Here, the phylomemetic tree could show us the cultural "kinship" of the emerged unity of the people lives in Indonesia. 


\section{References}

[1] Bryant, D. (1991). "A Classification of Consensus Methods for Phylogenetics". 1991 Mathematics Subject Classification DIMACS Series in Discrete Mathematics and Theoretical Computer Science.

[2] Davies, S. (2005). Themes in the Philosophy of Music. Oxford UP.

[3] Dawkins, R. (1976). The Selfish Gene. Oxford UP.

[4] Gündüuz, G. \& Gündüz, U. (2005). "The Mathematical Analysis of the Structure of Some Songs". Physica A 357: 565-92.

[5] Jan, S. (2000). "Replicating Sonorities: Towards a Memetics of Music". Journal of Memetics and Evolutionary Models of Information Transmission 4 (1). URL: http://jomemit.cfpm.org/2000/vol4/jan_s.html

[6] Kramer, L. (2002). Musical Meaning: Toward a Critical History. California UP.

[7] Levitin, D. J. (2006). This is Your Brain on Music: The Science of a Human Obsession. Dutton.

[8] Koeh (ed.). (2008). Kumpulan Lagu Daerah: Persembahan untuk Indonesiaku. Media Pusindo.

[9] Situngkir, H. (2007). "An Alternative Postulate to see Melody as “Language'”. BFI Working Paper Series WPK2007.

[10] Situngkir, H. (2007). “Menuju Studi Kompleksitas Musik Indonesia”. BFI Working Paper Series WPT2007.

[11] Situngkir, H. (2008). "Constructing the Phylomemetic Tree: Indonesian Tradition-Inspired Buildings". BFI Working Paper Series WP-III-2008.

[12] Snyder, J. L. (1990). "Entropy as a Measure of Musical Style: The Influence of a priori Assumptions". Music Theory Spectrum 12: 121-60.

[13] Soltis, D. E. \& Soltis, P. S. (2003). "The Role of Phylogenetics in Comparative Genetics". Plant Physiology 132: 1790-800.

[14] Temperley, D. (2001). The Cognition of Basic Musical Structures. MIT Press. 